\title{
COMMENTARY
}

\section{Is cytomegalovirus reactivation increasing the mortality of patients with severe sepsis?}

\author{
Andre C Kalil* and Diana F Florescu \\ See related research by Heininger et al., http://ccforum.com/content/15/2/R77
}

\begin{abstract}
Cytomegalovirus (CMV) is a ubiquitous virus present in approximately two-thirds of the healthy population. This virus rarely causes an active disease in healthy individuals, but it is among the most common opportunistic infections in immunocompromised patients such as solid organ transplant recipients, patients receiving chemotherapy for cancer or patients with human immunodeficiency virus. Critically ill patients who are immunocompetent before intensive care unit admission may also become more prone to develop active CMV infection if they have prolonged hospitalizations, high disease severity, and severe sepsis. The development of active CMV infection in these critically ill patients has been associated with a significantly higher risk of death in several previous studies. The present issue of Critical Care brings a new study by Heininger and colleagues in which the authors found that patients with severe sepsis who developed active CMV infection had significantly longer intensive care unit and hospital stays, prolonged mechanical ventilation, but no changes in mortality compared to patients without CMV infection. We discuss the possible reasons for their findings (for example, selection bias and low (20\%) statistical power to detect mortality endpoints), and also perform an update of our previous meta-analysis with the addition of Heininger and colleagues'study to verify whether the higher mortality rate with CMV holds. Our updated meta-analysis with approximately 1,000 patients shows that active CMV infection continues to be associated with a significant $81 \%$ higher mortality rate than that in critically ill patients without active CMV infection.
\end{abstract}

*Correspondence: akalil@unmc.edu

Department of Internal Medicine, University of Nebraska Medical Center, 985400 Nebraska Medical Center, Omaha, NE 68198, USA
In the present issue of Critical Care, Dr Heininger and colleagues present a new study in which they assessed the clinical outcomes of nonimmunosuppressed critically ill patients with severe sepsis who had reactivation of cytomegalovirus (CMV) [1]. They found that intensive care unit (ICU) stay, hospital stay and mechanical ventilation were all significantly prolonged in patients with CMV reactivation compared with those without reactivation, but the mortality rate was not different between groups. How can this be explained?

CMV serology is positive in over two-thirds of the healthy population based on epidemiological studies [2-4]. Similar to other herpes viruses, once an individual acquires CMV (mostly during infancy) the virus stays in a dormant phase for this individual's entire life. Conditions that lower the immune system guard may allow the dormant CMV to start replicating and lead to reactivation and an infectious state. Examples of these conditions include use of immunosuppressive drugs such as chemotherapy for cancer or anti-rejection therapy for organ transplant recipients.

Patients immunocompetent before ICU admission may become immunosuppressed due to severe sepsis [5,6], predisposing them to reactivation of viruses such as CMV. This hypothesis was supported by the results of a meta-analysis from our group [7], showing that the rate of CMV infection is influenced by the sensitivity of the diagnostic method, the type of ICU, disease severity, and the timing of CMV screening after ICU admission. We found that ICU patients with positive CMV serology at admission who stayed more than 5 days in the unit or who were admitted with severe sepsis were significantly more prone to have active CMV infection with a prevalence up to $36 \%$. In addition, we found that patients with active CMV infection had significantly higher mortality than patients without CMV infection (1.93, $95 \%$ confidence interval $=1.29,2.88 ; P=0.001)$. If such a higher mortality could be attributed to CMV or was in part secondary to CMV, then the results of severe sepsis trials could be substantially confounded from the very beginning [8]. In other words, even a small imbalance in CMV reactivation between control and treatment arms 


\begin{tabular}{|c|c|c|c|c|c|c|}
\hline \multirow[t]{2}{*}{$\underline{\text { Study name }}$} & \multicolumn{4}{|c|}{ Statistics for each study } & \multicolumn{2}{|c|}{ Deaths / Total } \\
\hline & \multicolumn{2}{|c|}{$\begin{array}{l}\text { MHodds Lower } \\
\text { ratiolimitlimit }\end{array}$} & \multirow{2}{*}{$\begin{array}{l}\text { Upper } \\
5.13\end{array}$} & \multirow[t]{2}{*}{$P$ value } & $\begin{array}{l}\text { ActiveCMV } \\
\text { fectionCMV }\end{array}$ & $\begin{array}{l}\text { Noactive } \\
\text { fection }\end{array}$ \\
\hline Domart Y 1990 & 2.18 & 0.93 & & & $16 / 29$ & $31 / 86$ \\
\hline Kutza A 1998 & 0.62 & 0.13 & 2.88 & 0.5400 & $7 / 11$ & $17 / 23$ \\
\hline Heininger A 2001 & 2.16 & 0.71 & 6.58 & 0.1744 & $11 / 20$ & $13 / 36$ \\
\hline Cook C 2003 & 2.76 & 0.74 & 10.35 & 0.1321 & $5 / 10$ & $25 / 94$ \\
\hline Jaber S 2005 & 2.64 & 1.04 & 6.69 & 0.0412 & $20 / 40$ & $11 / 40$ \\
\hline von Mueller L 2006 & 3.06 & 0.53 & 17.46 & 0.2091 & $5 / 8$ & $6 / 17$ \\
\hline Limaye A 2008 & 0.21 & 0.03 & 1.72 & 0.1465 & $1 / 39$ & $9 / 81$ \\
\hline Ziemann M 2008 & 3.26 & 1.11 & 9.54 & 0.0312 & $10 / 35$ & $7 / 64$ \\
\hline Chiche L 2009 & 2.08 & 1.04 & 4.17 & 0.0396 & $23 / 39$ & $83 / 203$ \\
\hline \multirow[t]{2}{*}{ Heininger A 2011} & 1.08 & 0.44 & 2.65 & 0.8608 & $13 / 35$ & $18 / 51$ \\
\hline & 1.81 & 1.31 & 2.50 & 0.0003 & $111 / 266$ & $220 / 695$ \\
\hline
\end{tabular}

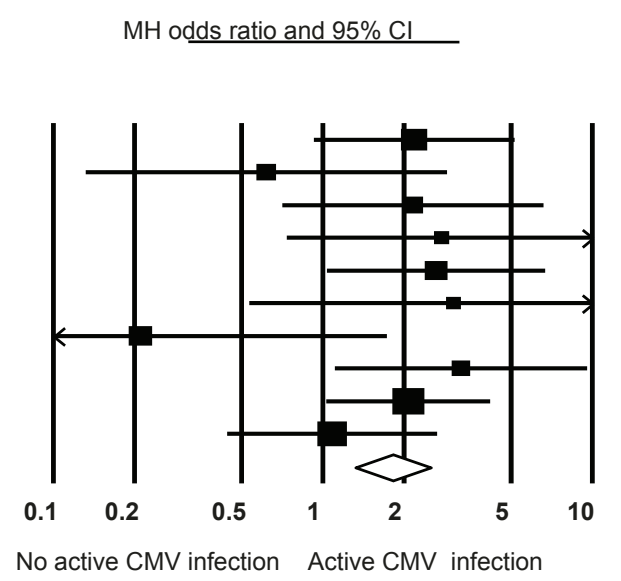

Figure 1. Active cytomegalovirus infection: all-cause mortality. $Z=3.62 ; P=0.0003 ; Q=10.01 ; R=10.9 \% . C l$, confidence interval; $C M V$, cytomegalovirus; MH, Mantel-Haenszel.

could lead to significant false-positive results due to more active CMV infection and higher mortality in the control arm; or to false-negative results due to more active CMV infection and higher mortality in the treatment arm.

This new study by Heininger and colleagues showed a significant association between active CMV infection and major morbidity findings such as prolonged ICU/hospital stay and mechanical ventilation, but no increased mortality [1]. Even though this was a well-performed observational study, however, the lack of randomization probably led to selection bias; for example, patients without active CMV infection compared with patients with active CMV infection had more septic shock and peritonitis, less urinary tract infections, and higher Simplified Acute Physiology Score II/Sequential Organ Failure Assessment scores - all of which are known to be associated with higher mortality. Hence, this small nonrandomized study could easily have been confounded by these important baseline imbalances, which could be the reason for false-negative results; that is, the more severely ill patients (due to baseline imbalances) without active CMV infection did not allow the study to detect the expected higher mortality in patients with active CMV infection.

Also, based on Heininger and colleagues' small sample size, the statistical power to detect differences in mortality between groups was extremely low (20\%), which could have further increased the probability of falsenegative results. If we assume that this high likelihood of false-negative results is true, then the addition of this new study to our previous meta-analysis should not change our previous results of higher mortality with active CMV infection. If we assume that their results are not false-negative, then the addition of this negative study should change the results of our meta-analysis. In order to clarify this assumption, we performed an update of the mortality analysis from our previous study. To be complete, we also added the study by Chiche and colleagues that was published after our meta-analysis [9]. Two more studies were thus added to our initial metaanalysis and the results are shown in Figure 1. Our updated results consistently show that active CMV infection continues to be associated with a significant $81 \%$ higher mortality rate than that in patients without active CMV infection. This finding strongly suggests the results from Heininger and colleagues were false-negative with respect to mortality outcomes. In fact, their worse morbidity outcomes in patients with active CMV infection fit perfectly with both previous studies and our recent meta-analysis, as well as with the higher mortality seen in patients with active CMV infection.

Based on all current evidence, it is unquestionable that active CMV infection is associated with higher morbidity and higher mortality in critically ill patients who were not previously immunosuppressed. Nonetheless, the million-dollar question still remains to be answered: is CMV causing mortality or is CMV accompanying mortality (that is, reflecting higher severity of illness)? Only a large prospective, randomized, non-interventional cohort study with adequate statistical power and comprehensive study design as previously recommended [8], can bring light to resolve such an important issue for our critically ill patients.

\section{Abbreviations}

CMV, cytomegalovirus; ICU, intensive care unit.

Acknowledgements

The authors thank Ms Ashley Calhoon for the excellent administrative support.

\section{Competing interests}

The authors declare that they have no competing interests.

Published: 24 March 2011 


\section{References}

1. Heininger A, Haeberle HA, Fischer I, Beck R, Riessen R, Rohde F, Meisner C, Jahn G, Koenigsrainer A, Unertl K, Hamprecht K: Cytomegalovirus reactivation and associated outcome of critically ill patients with severe sepsis. Crit Care 2011, 15:R77.

2. Stanberry LR, Rosenthal SL, Mills L, Succop PA, Biro FM, Morrow RA, Bernstein DI: Longitudinal risk of herpes simplex virus (HSV) type 1, HSV type 2, and cytomegalovirus infections among young adolescent girls. Clin Infect Dis 2004, 39:1433-1438

3. Lubeck PR, Doerr HW, Rabenau HF: Epidemiology of human cytomegalovirus (HCMV) in an urban region of Germany: what has changed? Med Microbiol Immunol 2010, 199:53-60.

4. Dowd JB, Aiello AE, Alley DE: Socioeconomic disparities in the seroprevalence of cytomegalovirus infection in the US population: NHANES III. Epidemiol Infect 2009, 137:58-65.

5. Hotchkiss RS, Karl IE: The pathophysiology and treatment of sepsis. N Engl J Med 2003, 348:138-150.

6. Oberholzer A, Oberholzer C, Moldawer LL: Sepsis syndromes: understanding the role of innate and acquired immunity. Shock 2001, 16:83-96
7. Kalil AC, Florescu DF: Prevalence and mortality associated with cytomegalovirus infection in nonimmunosuppressed patients in the intensive care unit. Crit Care Med 2009, 37:2350-2358.

8. Kalil AC, Sun J, Florescu DF: The importance of detecting cytomegalovirus infections in studies evaluating new therapies for severe sepsis. Crit Care Med 2010, 38(10 Suppl):S663-S667.

9. Chiche L, Forel JM, Roch A, Guervilly C, Pauly V, Allardet-Servent J, Gainnier M, Zandotti C, Papazian L: Active cytomegalovirus infection is common in mechanically ventilated medical intensive care unit patients. Crit Care Med 2009, 37:1850-1857.

doi:10.1186/cc10093

Cite this article as: Kalil AC, Florescu DF: Is cytomegalovirus reactivation increasing the mortality of patients with severe sepsis?. Critical Care 2011 15:138. 